\title{
Ultrafast Diagnostics for Electron Beams from Laser Plasma Accelerators
}

\author{
N. H. Matlis, M. Bakeman, C. G. R. Geddes, T. Gonsalves, C. Iin, K. Nakamura, \\ J. Osterhoff, G. R. Plateau, C. B. Schroeder, S. Shiraishi, T. Sokollik, J. van Tilborg, \\ Cs. T6th, W. P. Leemans \\ Lawrence Berketey Nanonal Labow atory, I Cyetowan Rd, Berkeley. CA 94720
}

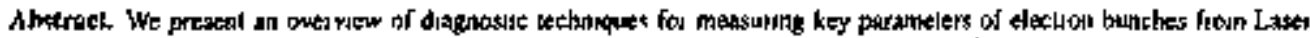

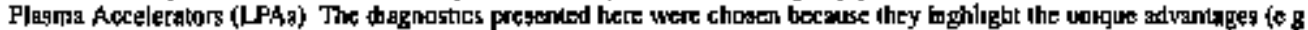

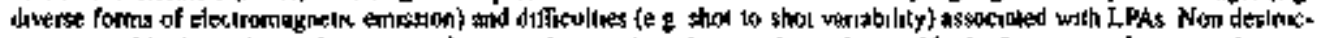

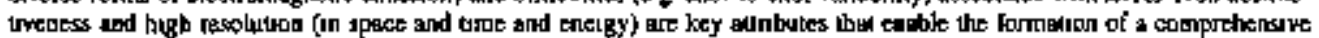

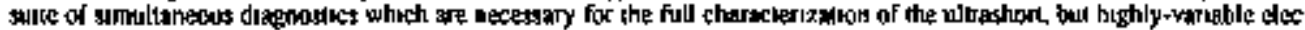
tron bunkheg from T.PÁg

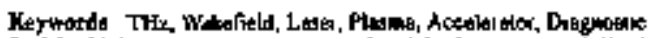

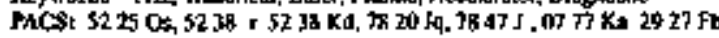

\section{INTRODUCTION}

Laker Plassma Acceleratort (I.PAs) ate becoming increasingly iniporianl as compact sources of high-encigy tlocIrons As thrs technology beguns to matule, a wide vas wely of applicauros, from high-energy culluders to free-electron

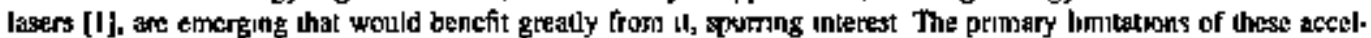
erators impeding their applicalion in general include their lack of shot-to-shot stabilsty and the lack of fine-luning of

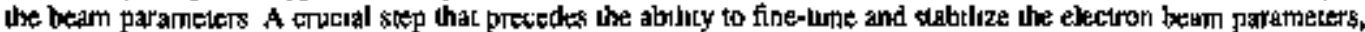
however, is the abilily to measure them As a result, a significant locus of LPA reacarch has boce dedreated to the development of diagnostlc rechnsques |2| While the fiett of eleclrom beam diagnosis if conventrongl accelerators is

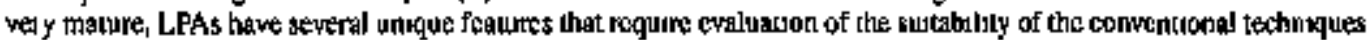

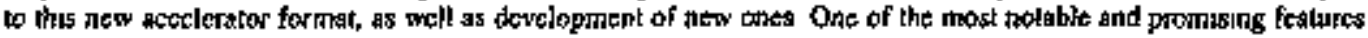
of LPAs is therr ability to produce electron bunches of exisemely shot durations, whech axe expected to be in the few femtosecond regime While such shorn duations are very desirable for many applicauchs, they can be exceptuonsally

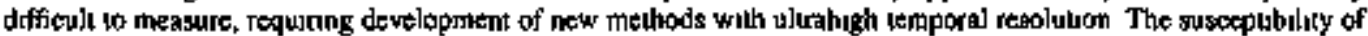
LPAs to shon to-shot fluctuations in the beam paranders is their ofher salient featune hectase of this high variability.

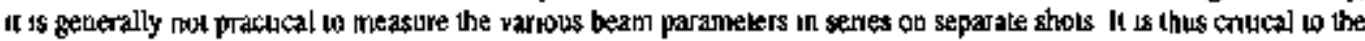

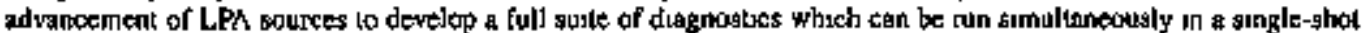
This reguirement implies the necessily of non destructivestess un these diagnothics Hete we presenl an overview of sewerd dlaynuzics whucb call be used in parallel to measure charge, energy, energy spread, emitlancu and longiturinal

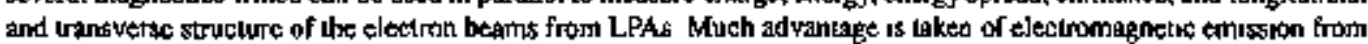

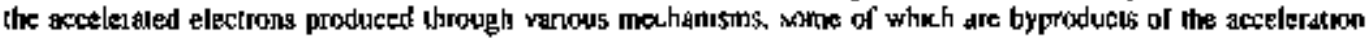
process

\section{CHARGE DIAGNOSTICS}

Integrating Coment Transformers (ICTs) have become standard insinuments ion the measurement of charge in

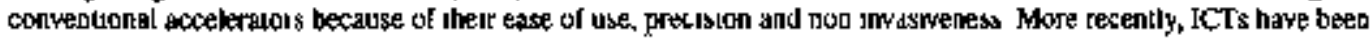
onducal tools for the LPA epriminuly as weil Because of the impartance of accorale absolute charge meaturement tor a large mumber of labs (unchudmg medical insilutuonsu). maby lests hawe been done to venfy the acearracy of ICTs for electron butnches with durations typical for conventronal accelea arors No bunch-length dependence has yel 

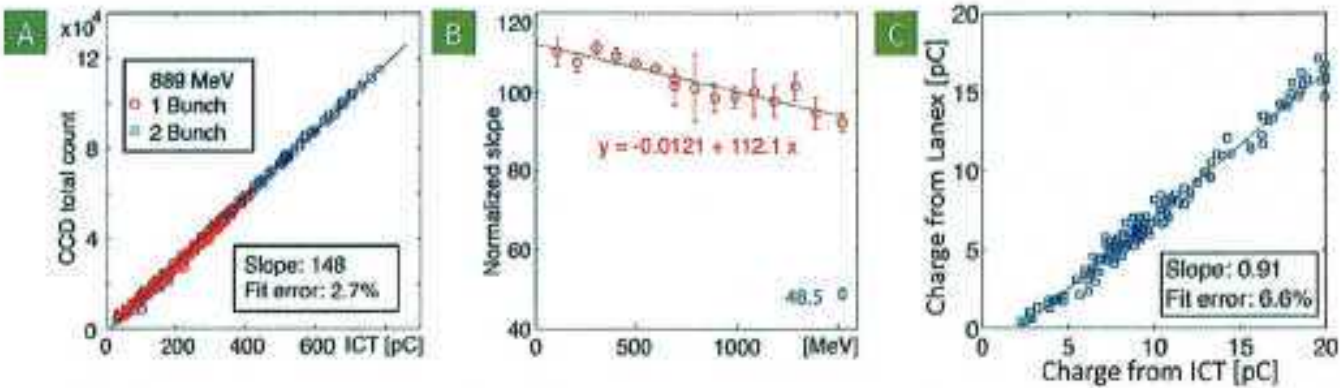

FIGURE 1. Comparison of [CT:based and Lanex-bused charge measurements. Courtesy of Nakamura et al. [6].

been reported in the range from microseconds down to picoseconds [3], but the regime of fs bunches has remained unconfirmed. Two recent studies $[4,5]$ reported discrepancies between charge measurements done with ICTs and scintillating screens, questioning the suitability of ICTs for use in LPAs. In the first experiment [4], discrepancies of greater than an order of magnitude, were observed. These discrepancies were attributed to the following potential problems: (1) that the ICT was not designed to measure sub-100 fs bunches, (2) the effect of electrons passing outside the core was not known, (3) that the electronic system was susceptible to electromagnetic noise generated in the interaction, and (4) that the ICT is sensitive to the large amount of low energy charge emitted at wide angles. In the second experiment [5], the ICT was found to overestimate the scintillating screen-based measurement by a factor of 3-4. The importance of ICTs to the LPA community combined with the doubt cast on them by these studies provides strong motivation for further detailed investigation into the applicability of ICTs to charge diagnosis in the harsh LPA environment.

A detailed series of experiments was recently done to cross-calibrate ICT-based charge measurement with two alternate methods of charge measurements based on scintillating screens (Lanex) and nuclear activation of a copper target [6]. In these experiments, the light yield from the Lanex screen was first calibrated using the electron beams provided by the synchrotron booster ring at the Advanced Light Source at Lawrence Berkeley National Lab (LBNL) in an energy range from $0.1-1.5 \mathrm{GeV}$ (Fig. 1a, 1b). A slight dependence of the light yield on electron energy was observed at the $1 \%$ per $100 \mathrm{MeV}$ level. Subsequently, an experiment was carried out on the LPA system at the LOASIS facility, LBNL using the three detection systems. Multiple steps were taken to ensure the accuracy of the comparison: 1) electronic noise was mitigated by using well-shielded cables, and the length of the cables was chosen in order to temporally separate the signal from the noise generated by the interaction; 2) the ICT was installed outside the vacuum tube, over a ceramic spacer to avoid the effects of electrons and laser light impacting the ICT, 3) the ICT was placed close to the Lanex screen, and an aperture was used to ensure a common angular acceptance for both detectors to avoid errors induced by the effect of large divergences of lower energy electrons; 4) the ICT and Lanex were placed sufficiently far from the interaction to ensure that a small residual magnetic field of $\sim 0.4 \mathrm{mT}$ would be sufficient to defiect $\mathrm{keV}$ electrons to which the Lanex screen may be insensitive. Comparison of the Lanex and ICT measurements shows agreement to within $\sim 9 \%$ (Fig, 1c) for bunch charges ranging from $0-20 \mathrm{pC}$. Analysis of the nuclear activation experiment likewise resulted in agreement with the ICT to within $\sim 7 \%$, for charge integrated for over an hour. The good agreement between these three measurements demonstrates that there is no intrinsic limitation of ICTs preventing their use in LPA systems. The previously reported discrepancies, however, indicate the importance of accounting for effects common to LPAs, such as the strong dependence of bunch divergence on electron energy, and of taking the proper measures to ensure reliable operation.

\section{UNDULATOR EMISSION}

One promising application of LPAs is the development of compact free electron lasers (FEL.s) as ultrashort sources of electromagnetic radiation from $\mathrm{THz}$ to $\mathrm{x}$-rays $[7,8]$. The high peak currents and ultrashort bunch durations of $\mathrm{LPA}$ electron bunches are ideal for the generation of high-brightness, coherent, short-wavelength radiation desirable for a wide range of studies, such as the reconstruction of the structure of complex biological molecules. The synchrotron 


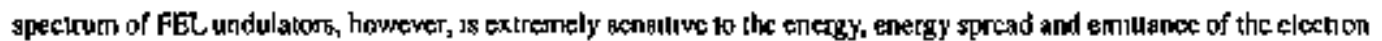

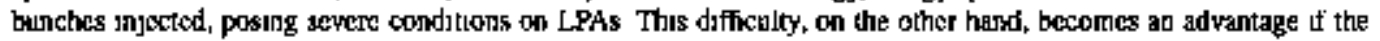
emisson spectum is used as a diaginosic of the electron bunches $[9,10,11)$ The cinnest slate of the art for measun ing

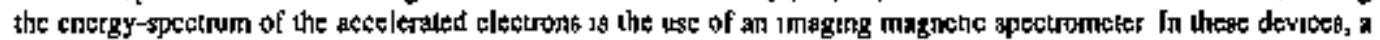
tunable magnetic field umages and spechally disperses the electrons in one plane Scinillating scteens (e g Lanex) are thest ussed to measure the distnbutuon of charge in the Fourier plane of the spectromerer, proyking single-sthol ipformation of the energy distrubution of the electrone erritled by the accelerator Thu approach is xdeal for LPAs because it proydes single-shot delection ove a liste range of energies, allowing diagnosis of both the low-energy Maxwellian tall of the bumch as well as the high energy "quast-Inonoenergeuc" component of the beam The diawback of uns meibod to that us order co resolve the full ratge of energes, from MeV to GeV, the energy resolution of the sevice may be limiled, especially al highet energies whete the disperbiun is smaliesl, resul ang its resolutions om the order of a coupk percent or more [12]

As progress in LPA develupment proceeds and researchers succeed tn pushung down the energy spread of the high. encrigy (GeV leve], mono-energetic component to the few pencent level atd helow [ 13 ], the measured energy aprearls

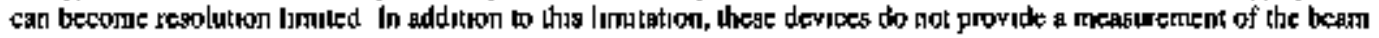
emittance, which is cnical fol many applications A powerful technique based on the characterpanon of undulator radiatton, however. can provide both high-Jesolution (< 0 ! \& Ims \{14]) energy spread and emitlance vjessurement on

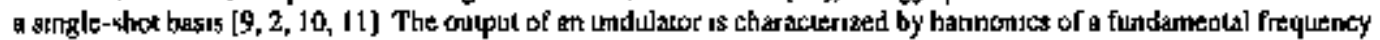
glues by [15]

$$
\omega_{B}=\frac{4 \pi c \gamma^{2}}{L r}\left[1+\frac{K^{2}}{2}+\gamma^{2} \theta^{2}\right]^{-1}
$$

where $L_{m}$ is the undulater purodictty, $K=e \beta_{0} L_{3} / 2 \pi m c$ is the strength paramoter, $\gamma$ is the Lorente factor for the oscillaling electrons, and $\theta$ is the angle of the elextron trajectory wilh respect to the axis of the unduialor Thus, for a given fel of undulacor parameters $L_{Y}$ and $K$, the on arus contubution to the bandwitth of the the hatmonic peak will be

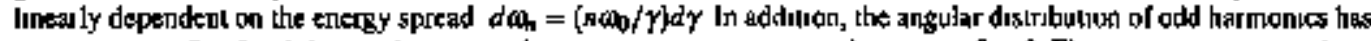

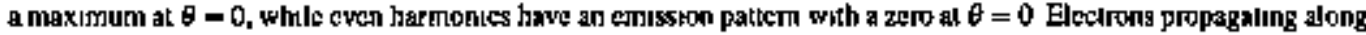
the undulator axis da nol contribule to the even harmonics while electrons propagaing off-axis do The ralio of eves to

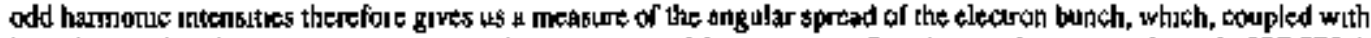
knowledge of the bunch source size, provides a measue of the emilisnce Sizullations done usmg the code \$PECTRA [16] for electron bunches with varying energy spiead and emuttance confirs the dependence of undolator spectral features on energy and emullance (Fig, 2) Experinients are cunenlly undet way to test the coucept [14, 17]

\section{BETATRON X-RAY EMISSION}

Synchirotran emission to also ensulted duing inlexacions or the electrons with the wakefield and can be used to gain information about the axceleraluon process itself Ejectrons pujected ofl axis into the wakefield expenctroe an

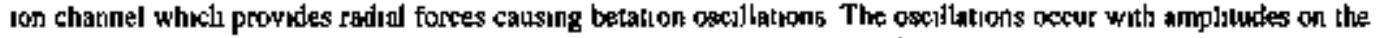
scale of few to hundteds of microns, determining the size of the elextron bunch, and resultung in emission of soit $\mathrm{X}$ rays in the few heV range, kuown as betatron tadiatuon The amplitude and pertodicity of the betatron coscellations depend senastively on the shape of wakefield, the physucs of the injecton, and the presente of strong $E$ fieldo frous the druve laser, thus the betalon $x$-rays can provide yaluable insight into the isature of the inieraction between the laser, the ejectrons and the plasma In addituen, as the belatron oscillation penod is much shotter than that which can be

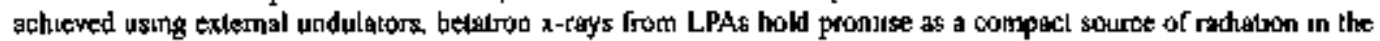
keV coegy range

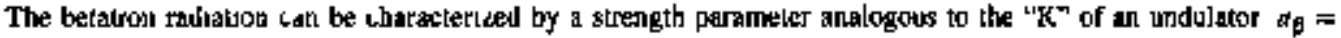

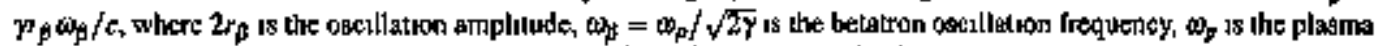
frequency and $c$ is the speed of light Vartous groups have demonstr ted the derecloon of betatcon radiatron from I.PAs.

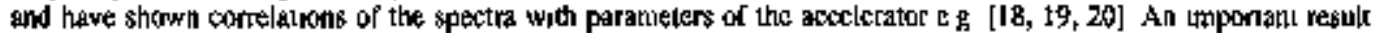
that has come from these meagurements is the detemsinaloon of the sourese saze of the H-[ays, which wal accomplished by placsng knufe-edges or wire meshes in the x-ray bearns and obscrvitic the shatpness of the shadow cast on an 1magung delector Source sizes varying froul $\sim 2 \mathrm{pm}$ to seversl hundred micious have been measured in dufferent

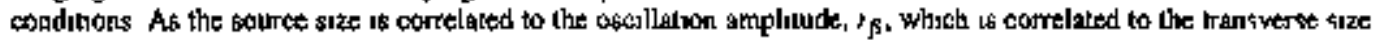
of the election buach, tlus technique provides valuable unfoumatom aboul bie physkes of the accekeration and the 

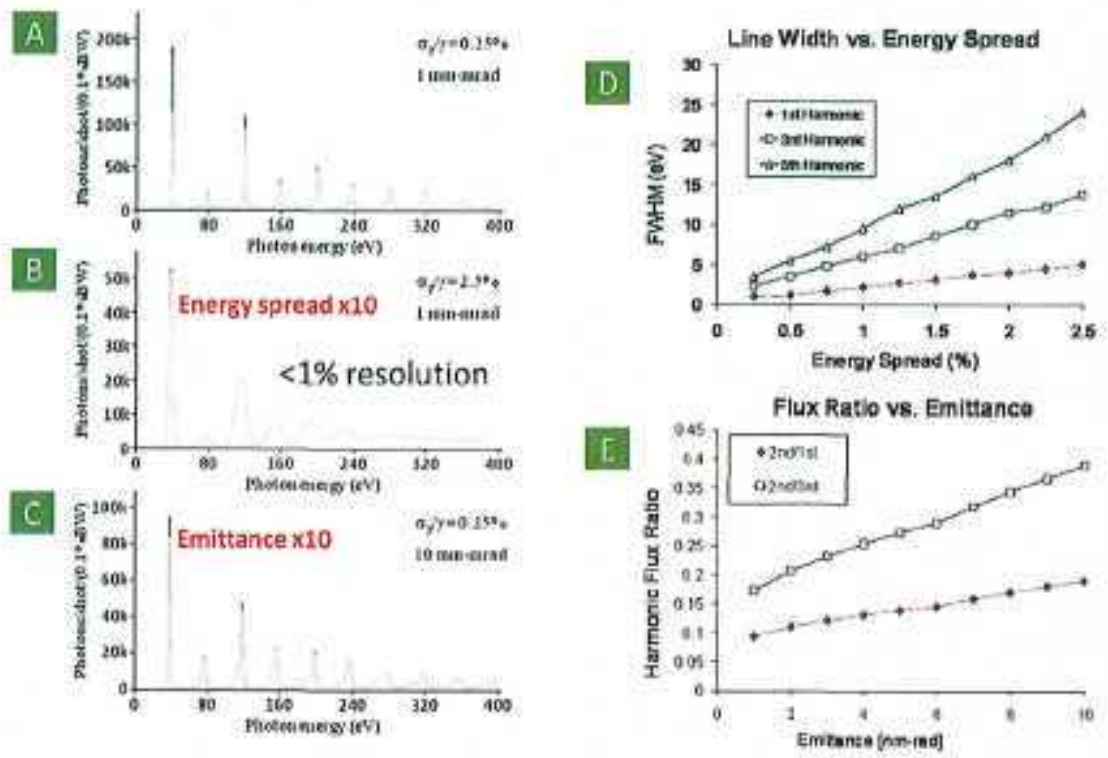

FIGURE 2. (A) Radiation spectrum from THUNDER undulator, $K=1.85, \lambda_{\text {periaf }}=2.18 \mathrm{~cm}$, energy spread $=0.25 \%$, emittance = $1 \mathrm{~mm}$ mrad, Calculated using SPECTRA. (B) Spectrum for 10-fold increase in evergy spread. (C) Spectrum for 10-fold increase in emittance. (D) Dependence of harmonic line-width on energy spread. (E) Ratios of $2^{\text {ind }}$ to $1^{\text {st }}$ and $2^{\text {nd }}$ to $3^{\text {rdd }}$ harmonic intensities as a function of the emittance. Courtesy of Bakeman et al. [10]

quality of the accelerator. These measurements also provide precise information about the shot-to-shot variation in the emission point of the electrons, which can be used to determine the stability of the accelerator. In addition, because the spectrum of the $x$-ray emission is dependent on both the electron density of the plasma and the energy of the accelerated electrons, it can be used as a probe of the acceleration physics (e.g. $[19,21])$.

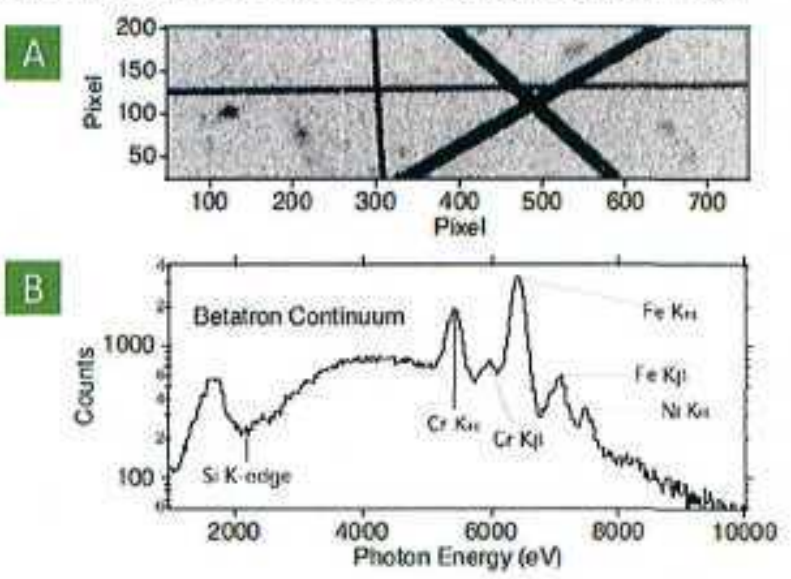

FIGURE 3. Betatron radiation fiom the LOASIS LPA back lighting 2 pairs of erossed wires of dianneter $12.5 \mu \mathrm{mit}$ and $50 \mu \mathrm{m}$ Courtesy of Thorn et al. [18].

Spectral measurements have previously been done in a multi-shot configuration in which the variation in $x$-ray yield was observed as a function of different filters placed in front of the detector. This approach is time-consuming, provides 
low speciral regolution, and cannot be used to conclate indiv/dual X.ray spccten with associated elechon specira

In a rocent Jcpor [18] a lechnique was implemented to recond measuemenis of single-shot, spatially tesolved spectra of betatron x-rays with high spectral resolution, by the use of an k-ray CCD Images analyzed by peilorming

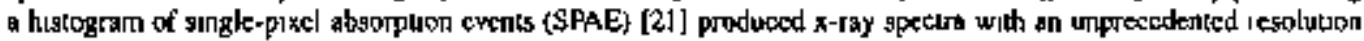
of $225 \mathrm{eV}, \mathrm{FWHM}$, and a range of ower $10 \mathrm{kgV}$ A soturce emitung iros $\mathbf{k}$ shell $x$-ray lines was wsod to provide * calibration of the eneryy por puxcl count Preliminary diala show two imporlant features not prevrously tesolwed The

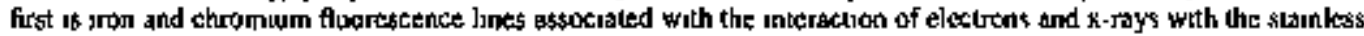

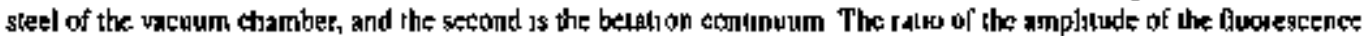
lines to that of the betauron contınuur was found to yasy signuficantly with changes in the accelerabor parameters, calling into questuon the validity of pnevious spectral analyses, besed on filter packs, whish winnot dibunguish betwreen these two components

\section{ELECTRO-OPTIC DIAGNOSTICS}

Electronopuc (EO) sampling has become a whicly-used icchusque for the measuternent of clcctron-bunch durations and temporal struclure in this technmue, esther the relauysuc Coulomb fiedds of the electron bunct or cohetent transolion (adianion (CTR) in the THy trequency bathd emiled by the electron bunch traversing a diclectinc houndary Is used to indues brefingenec in an cleuro-optcally aclive crystal, auch as galloum phosphide (GaP) or zune telluride (ZnTe) An optcal probe, timed in overlap with inese stong elecirc fields, is uted to sample the temporal profile of the fields, ftom which un: duration of the electron bunch can be deduces Thus techutique is very powerful because 11 ean be uged in configurations that art non- or wrakly-minteractedg with the electren bumch, allowing it to be used in conjuscuon wilh other diagnostics In addiron, it provides the high kemponal rebolutions reguired for measuring the sub proosecond eleciron butches produced in LPAs The EO samplung process can be spht into two conceptual parts

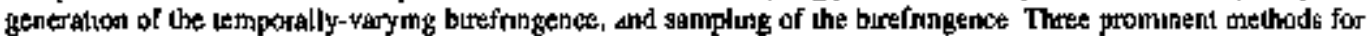
esch will be discussed

Genernting the birefirlngence. In the first method (Durecl Coulomb Sampling), the EO wyslal ts placed near lo the path of the accelerated electrons, so that the Coulomb tields penettate $1 \mathrm{t}$, resulung in a transent birefretrgence An

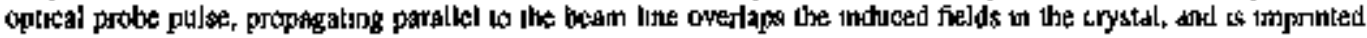

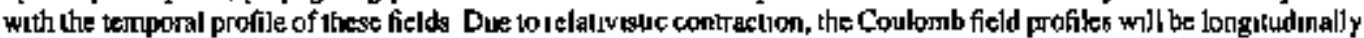
compressed by an anount dependent on the electron energy The ficld tomporal profile will thus be a conwolution of the

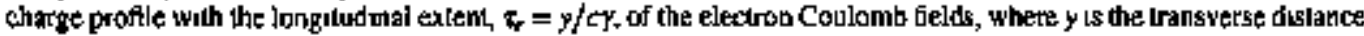

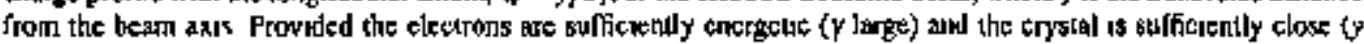
small), the field profile wall represent the bunch profile wetl In general, lipwevor, a polychomatic electron bunch will have a fleld profile (at the cryblal) signtficantly diffenent than tt charge prohle, with the lower conergy clicctrons

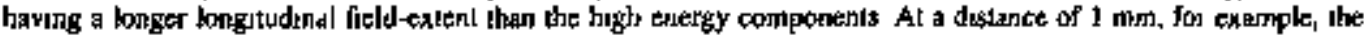
corvoliuica factior will be approximately $17 \mathrm{ps}$ for a $1 \mathrm{MeV}$ cormpothent whle it will be about I I f6 for a $1 \mathrm{GeV}$ congoment In addition, since the field-5trengh scales as $\gamma$, the EO signal will be strongly biased towarts the high energy componient of the slectron butsch In scenarios where it is the behavior of the bigh-entergy component that

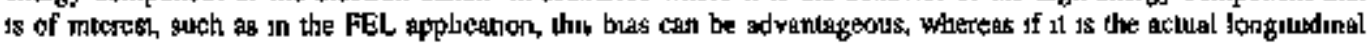
charge distribulion tbal is desired, this approach may not be suitable In RF accelerators (e 8 [22, 23]) whene this technique has been demonstrated, the electron buiches have wuficsenl enctgy and spectral purity that this ussue is not

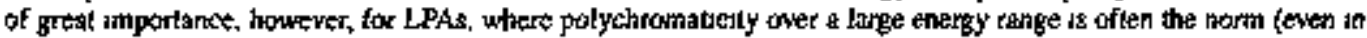

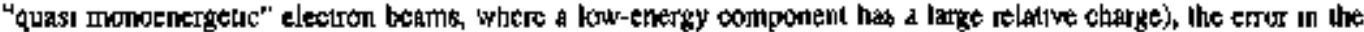
measurcimenl of the kngludinal charge profile may be large

In the second meihod (Fosl CTR Sacupling), a tod] is placed in the path of the electrons resulting tn the gereration of trensithon I

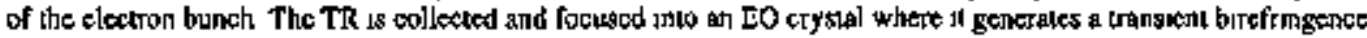
sarupled wilh an optical probe The spectrum of the TR is connelated to the temporis profile of the electron bunch [24] due to a strong coherent enhancement for warclengths konger than the duratuon of the eleciron burch The spectrat ahape can thus be used to analyze the bunch longitudinel peofile. In this case, the dependente of the collected CTR energy is relatively weak on the $y$ of the electrons, so gleigy-buasing it minitrat A sirong dependence of ithe angular distribution of the CTR energy with wavelenght, howeya, means that i corrod anslysis of the CTR specirum must Lake into abcount the spectually-dependeal collection efficrency of the opical system In addition, sibce the remse of cosllected Irequencies can be very large, the vanatiog in effective f number and focus size with wavelength can be very 


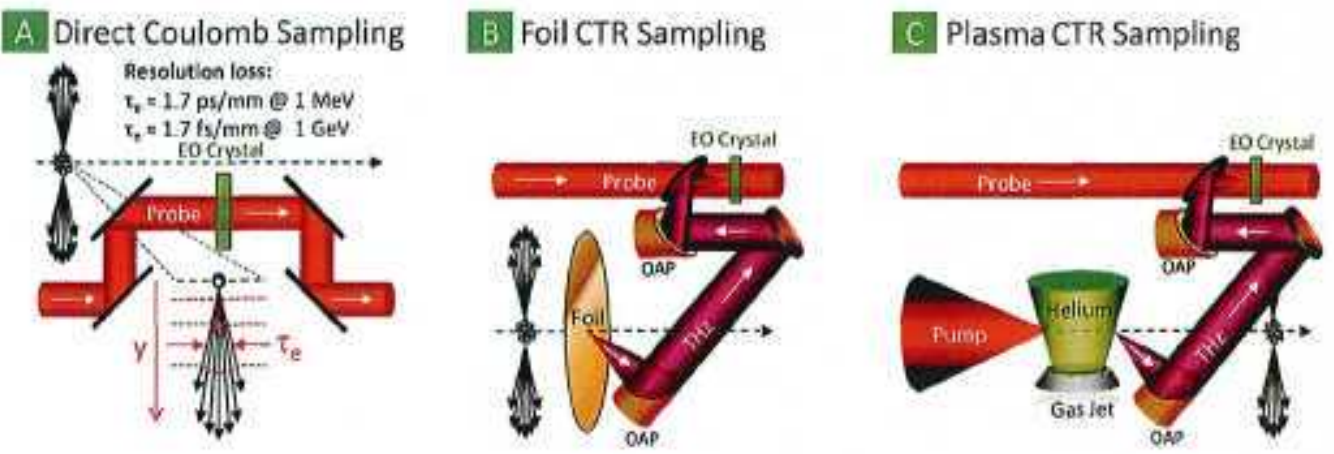

FIGURE 4. Selups for sampling (A) bunch Coulomb fielés (B) CTR fron a foil (C) CTR from a plasma-vacuum interface.

significant, leading to a reshaping of the spectrum at focus compared to the collection point [25]. Finally, aberrations in the optical system may induce distortions which can produce artifacts in the measurement [26].

In the third method (Plasma CTR Sampling), CTR is collected directly from the plasma-vacuum interface at the cxit of the acceleration region [27]. This method is very similar to Foil CTR Sampling, except that there is no foil to interact with the electrons, so it is truly non-destructive; the collection is off-axis, avoiding the high-intensity of the transmitted laser, and the CTR is collected directly from the output of the accelerator, ensuring that there is no bunch expansion before the measurement. Although the plasma-vacuum boundary is not as sharp a discontinuity as a foil. it can be adequately modeled as a sharp boundary provided the region emitting the CTR is smaller than a distance known as the "formation length" [28].

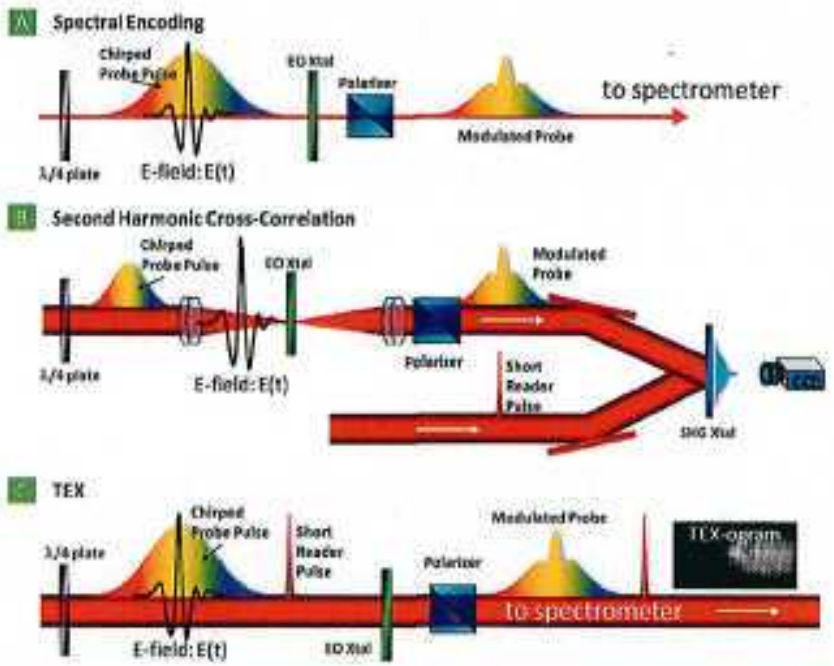

FIGURE 5. (A) Spectral Encoding (B) Second Harmonic Cross-correlation (C) Temporal Electric-ficld Cross-comelation (TEX).

Sampling the birefringence. Early methods for sampling the birefringence employed an optical pulse shorter than the features to be measured, i.e. the wavelength/duration of the E-field. The polarization rotation was converted to an amplitude modulation by a polarizer, and the intensity variation was recorded using a photodiode. Due to the highly variable nature of LPAs, and hence of the fields to be profiled, a multishot approach results in a washing out of the higher-frequency features which contain information about the bunch duration. As a result, a high priority is placed on the ability to perform single-shot accuisition of the field profiles. The first technique ereated to do this was known as "Spectral Encoding" [29]. In this technique, the optical probe was sent through a dispersive element 
(e p a compressor/streicher) resulting m tcmporal chirg, i e a mapping between wavelength and timc The transicnt barefringence was then encoded as \& spectral ampintude modulatron that could be measured in a spectiomeler This

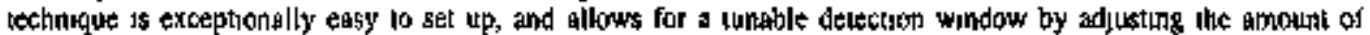
churp Unfortunalcly, the wiscleggth-to tore mapping is affecled by the amplitude modulation, resuling un distortions [30, 3I. 32] The severty of these destocions is dependent on the shappess of the feature beng measured, so this rechnrque is more sulted to measuraments with low temporal resolutron (e o in the pacosecond regime)

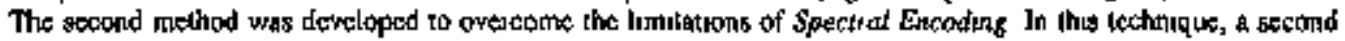
short optcal pulse is combined with the chirpod probc in a single-sbor cross-correlator genmetı The two pulses are combined at an angle in a second hamonke crystal, mapping time to space, resultong in a spatial intensily pattern.

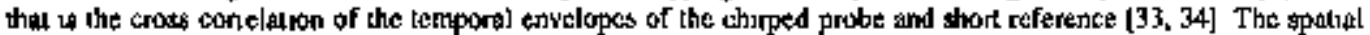

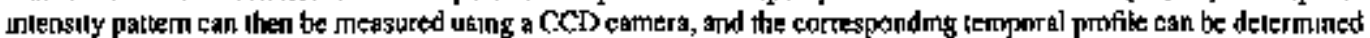
usung the appropnate calibration this method has been sucocssfully used in bath conyentional acoelerators [23] snd un LPAs [33] to measure electuon bunch probles whth high temporal reso]ution (10s of fs) This techniquw, however, hat the disadvantage that it tegutres high probe iniensities, and this expents\%e ampisi fied lasers in order to get arlequate signal In addition, because the kemporal signal is enooded spatudly and the probe laser is focused at the interactron, spatial thformation oboul the THz pulses is lost As the TLlz pulses in many of theso applications dfe fow-cycle.

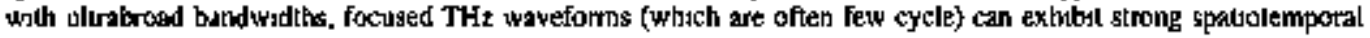

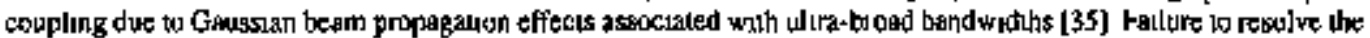
spatial yaraalions can thereforc result in a less of cлucal informition

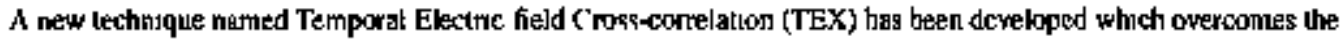
above limitariens, alkowing measurement of THz waweforms w ith high temporal resolution (sub $50 \mathrm{fs}$ ), simultaneously plow ding onc dimension of spathal information [25] T'EX us hased upon thesasurement of the linceir cross-somelation of a churped probe with a compressed reference pulse using spectral interferometry The full electnc-field informalion

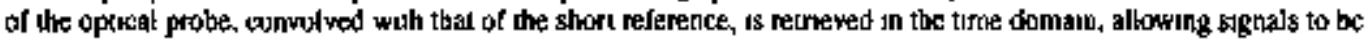

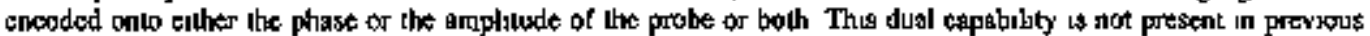
EO methods, and makes TEX applucable to the measurement of a wide range of phenromena beyond EO samplang Because the detectrots is linear, TEX can be implemented w1th low-cosh, unamplified laser systens, and because it does nol require focusmg of the optucel proter, spattal informalon can be recorded aud retrieved In addatson, the

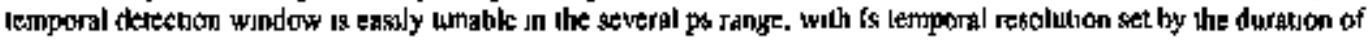
the short reference pulse

In TEX, a churped "probe" pulse samples the birefingence and is then combuned colinearly wilh a oecond shour "reader" pulse in an imaging sfectrometer A iemporal sepirtation of several prenseconds belween the lwa pulses (which have identical spectral content precodjng the inkreaction) caluses an inierference paltenu in lhe spectral domaln (FIg 6A) wheth is desconbed by $S\left(\omega_{1}, y\right)=\left|E_{f}(\omega, y)\right|^{2}+\left|E_{p}(\omega, y)\right|^{2}+E_{p}(\omega, y) E_{1}^{-}(\omega, y)+\varepsilon c$ whete $E_{D}(\omega, y)$ and

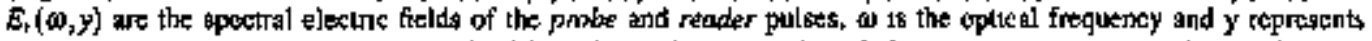
the vertical, undispersed coordinake on the CCD The probe amplrtude and phase siructure is recovered by performiag a line-by lue, Fountr-traisform (FT) of the interferogram and solaing the sude peak whsch, by the conrolution

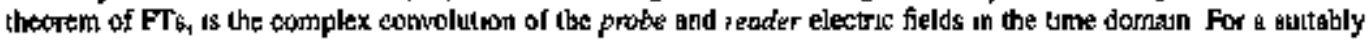
short regder pulte. the side peak of the FT approximtates the clminsed probe pulse in both amplotude and phase

$$
F T\left[E_{p}(\omega, y) E_{\alpha}^{2}(\omega, y)\right]=\int_{\infty}^{\infty} E_{p}(\tau, y) E_{\alpha}^{\prime}(\tau-t, y) d \tau \approx E_{p}(t, y)
$$

Figure 6E shows a sample THz spatiocempor al waveform umage acquired using TEX to sample platmo CFR un the

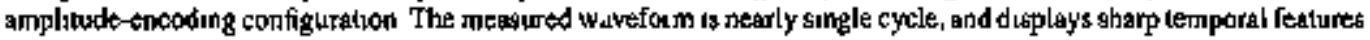
of older $100 \mathrm{fs}$, illusirating the reed for high temporal regolution The wave form also exhubits strong spatroternporal coupling, in the shape of an $\mathbf{X}_{1}$ as was detcribed by Jiang el af [35], which can be underslood In terms of a yaution

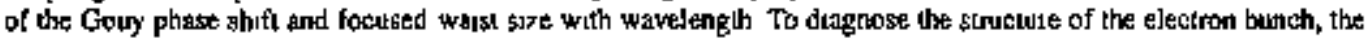

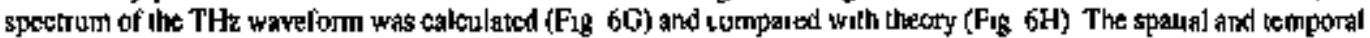
feutures of the spectral inage were modeled by using CTR emission the ry [24] with the inclusion of culkelion and propagation effects To accuralcly model buth the low- and high frequency pats of the special image, two bunches

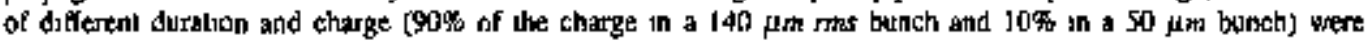

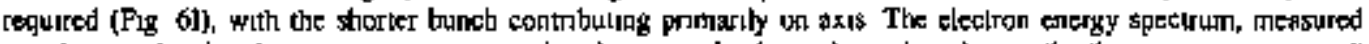

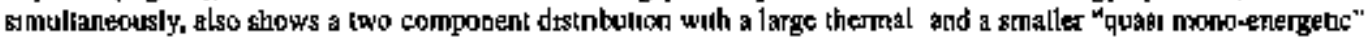
component The importance of recovenng the spatal warsations in the THz wave[orms is illusirated by the shong 

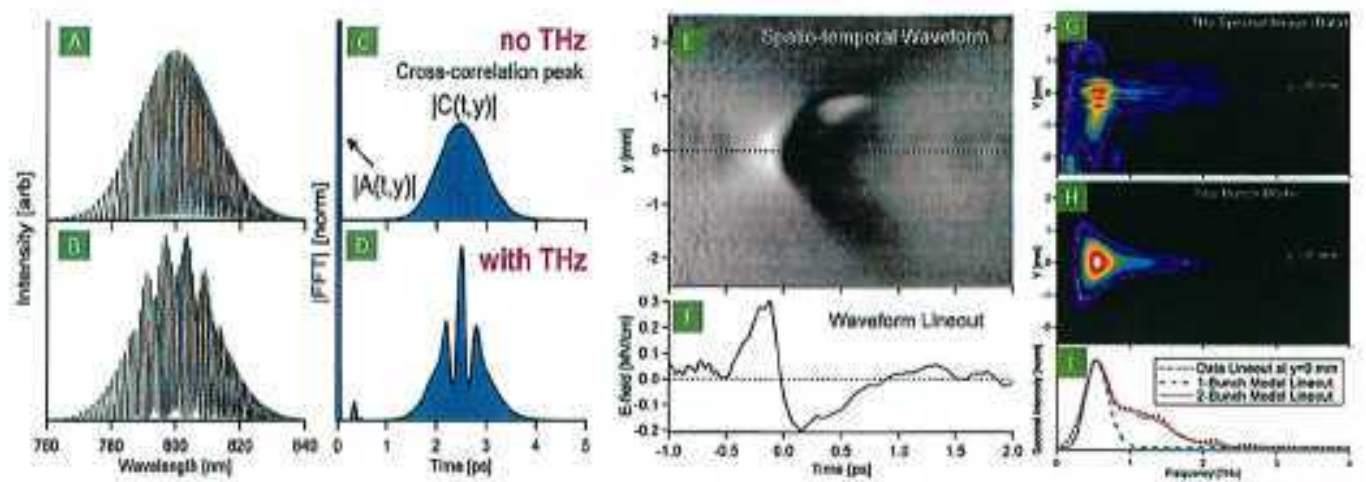

FIGURE 6. (A) Stinulated TEX interferogram in the absence of THz for probe and reader pulses separated in time by $2.5 \mathrm{ps}$. (B) Simulated TEX interferogram with THz present. (C) Modulus of the Fourier transform of the interferogram in (A) showing a broad side peak at $2.5 \mathrm{ps}$ which represents the amplitude of the cross-correlation between the pmbe and reader electric-fields. (D) Modulus of the complex Fourier transform of the interferogram in (B), stoowing a THz-induced modulation in the side peak amplitude. (E) $\mathrm{THz}$ spatiotemporal waveform (data) extracted from the raw interferogram. (F) lineout of waveform at $y=0 \mathrm{~mm}$. (G) Power spectrum of THz wayeform. (H) Spectral image calculated using a 2 -bunch model and (I) lineouts of spectral images for data (black-dotted line), 1-bunch model (blue-dashed line) and 2-bunch model (red-solid line), Comparison shows that a 2 bunch model yiekds a significantly better fit than a I-bunch model. Courtesy of Mallis et al. [2S].

variation with position of spectral content in the focused $\mathrm{THz}$ pulse, A spatially-integrated technique would underrepresent the high-frequency content of the $\mathrm{THz}$ spectrum associated with the shorter electron bunch component, thus distorting the analysis. In addition, because the spatial extent of a given spectral component is strongly dependent on both the wavelength and the wavelength-dependent $\mathrm{f}$-number of the $\mathrm{THz}$ emission, the correspondence between the data and the model provides an important confirmation that the collected $\mathrm{THz}$ follows the emission patterns predicted by CTR theory, verifying its origin.

\section{CONCLUSION}

We have presented a suite of diagnostics, designed to handie the advantages and disadvantages inherent in LPAs compared to conventional RF accelerators. The diagnostics have been chosen because they provide non-destructive measurement of the key attributes of the accelerated electron bunches in a single-shot format. These diagnostics include ICTs for charge measurement; undulators for energy, energy spread and emittance measurement; betatron $x$-rays for source size measurement; and electro-optic sampling using TEX to sample CTR from the plasma-vacuum interface for electron bunch temporal profile measurement. Formation of a comprehensive suite of diagnostics to measure the attributes of the electron bunches in a single-shot is a critical step for enabling the studies of the complex interdependence of beam properties which will help drive the field of laser plasma acceleration to maturity.

\section{ACKNOWLEDGMENTS}

This work was supported by the Director, Office of Science, Office of High Energy Physics, of the U.S. Department of Energy under Contract No. DE-AC02-05CH11231, DARPA, DTRA and NA-22.

\section{REFERENCES}

1. W. P. Leemans, and E. Esarey, Phys, Today 62, 44 (2009)

2. P. Catravas, E. Esarcy, and W. P. Leenans, Phys. Plasmes 9, 2428 (2002).

3. J. Bergoz, Integrating current transformer (ict) pulse charge aceuracy. Technital Note ICT / 06,1. Bergoz Instrumentation (2006). 


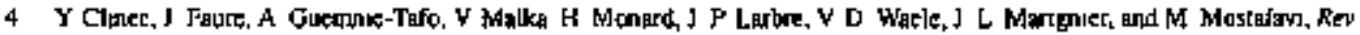
So Intring $77,103301(2006)$

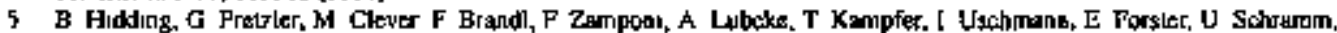

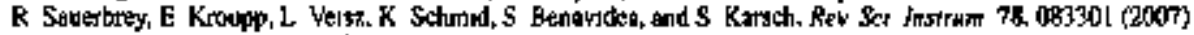

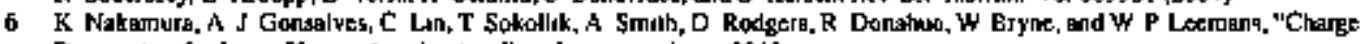

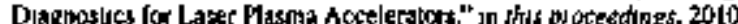

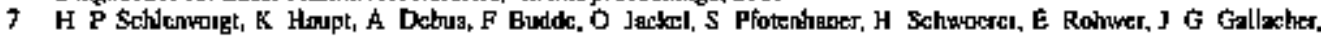

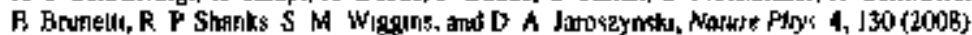

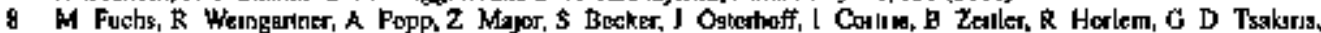

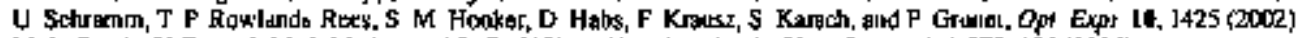

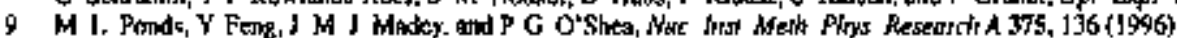

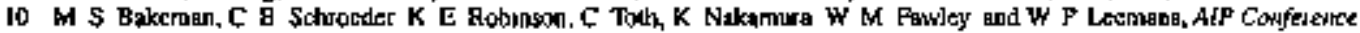
Proctedings 1086, 643-646 (20109). URL httP: $/ / 11$ ink a 1 p org/ $/ 1$ nk/ $/ 2 \mathrm{KPC} / 1086 / 643 / 1$

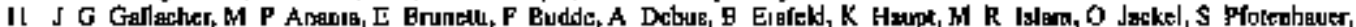

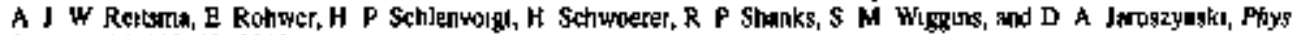
Plianas 16, 093100 (2009)

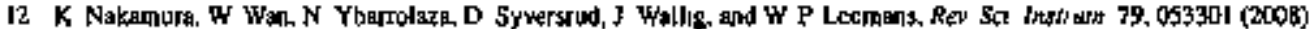

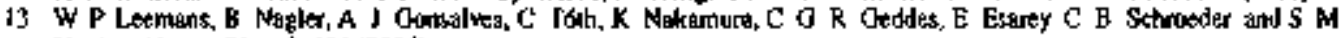
Hooker. Noture Plyys 2, 696 (2006)

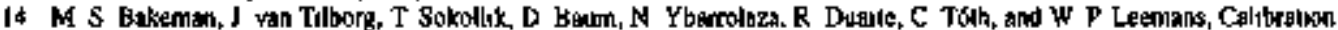

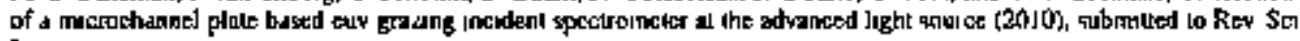
Instrum

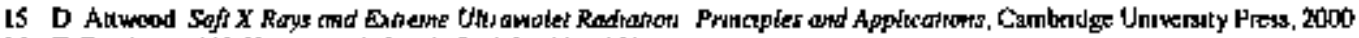

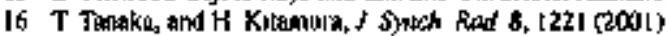

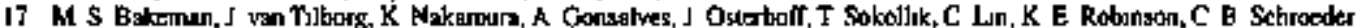

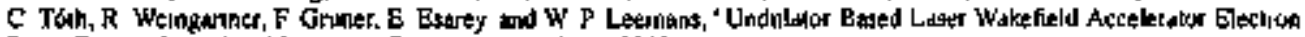

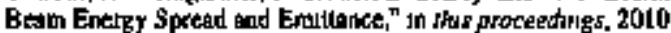

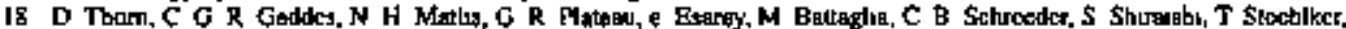

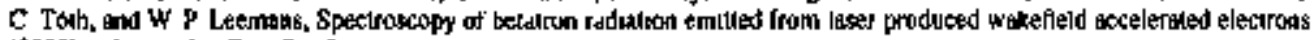
(2010), submitted to Ray Sct loetrum

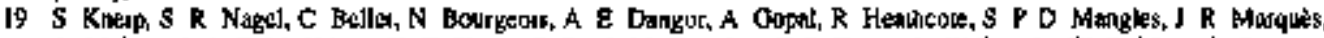
A Asaksimchuk, P M Nilson, $X$ T Phuoc, S Reed, M Troufras, F S Tsung L Wollingale, W B Mon, A Rnumse, X Krustieleldk, and Z Naimudin, Phys Rer Latd 100, 105006 (2008)

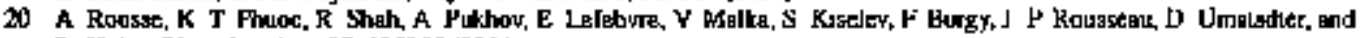
D Huln Phys Rev Let 93, I35005 (2004)

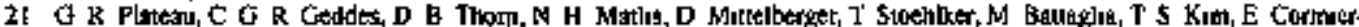

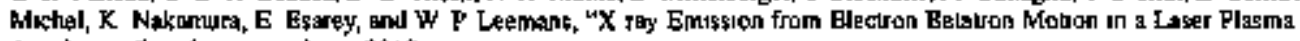
Acielerrier, in thrs procededisgs, 2010

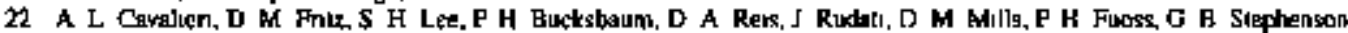

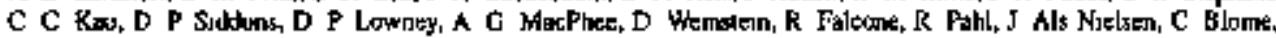
S Dulskerer, R Jschebeck, H Schlab, H Sehulte Schrepping, T Tichenischer I Schneader, D Hugneste. F Sette,

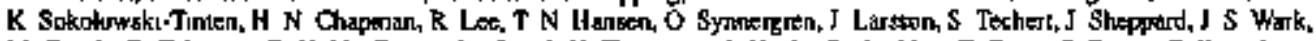

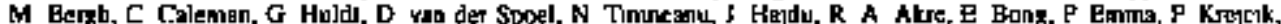

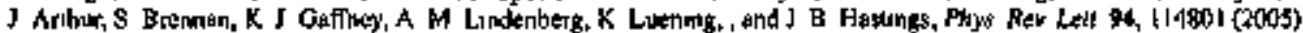

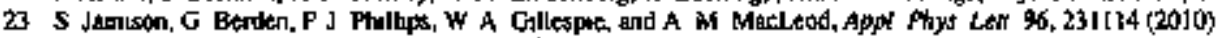

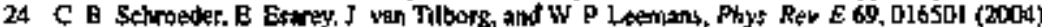

is N H Aarlis, 0 \& P I y using temporal electroc field oross correlation (2010), accepped J Opt Soc Am E

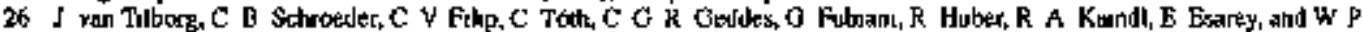
Lemans, Phys Rev LeV 96,01480 (2006)

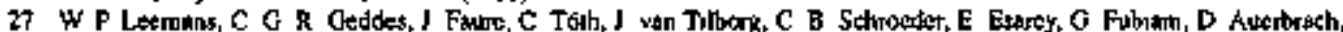
B Marcedus. M A Camahan. R A Kandl, J Byrd, and M C Marlun. Phps Rev Let' 9], 074802 (2D03)

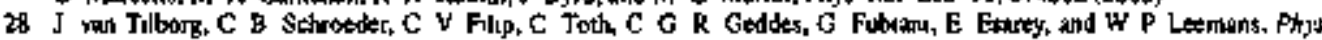
Plashers 13. 05670A (20106)

$29 \mathrm{Z}$ Jang, and X C. Zueng, Appt bhys fert 72, 1945 (1998)

30 P G Sua, Z Jieng, and X C Zhung Apo' Plars Lett 732233 (1998)

3] I R Flecher, Opt Expr 20. 1425 (2002)

$32 \mathrm{X} Y$ Peng, $O$ Wult, $M$ Chen, and A Pukhoy, Opt Express 16, 12342 (2009)

33 S Jamison. S Shen, A M MacLeod. W A Gillespe, and D A Jaroszyngki, Opt Letr 28. 17$] 0$ (2003)

34 J van Tiborg, C B Schroeder, C 16th, C G R Geddes, E Eaurty, and W P Leemons, ON Lett 32, 313 (2007)

$35 \mathrm{Z}$ Jieng, and $X$ C Zhang Opt Express 5.243 (1999) 


\section{DISCLAIMER}

This document was prepared as an account of work sponsored by the United States Government. While this document is believed to contain correct fnformation, neither the United States Government nor any agency thereof, nor The Regents of the University of California, nor any of their employees, makes any warranty, express or implied, or assumes any legal responsibility for the accuracy, completeness, or usefulness of any information, apparatus, product, or process disclosed, or represents that its use would not infringe privately owned rights. Reference herein to any specific commercial prodtuct, process, or servicc by its trade name, trademark, manufacturer, or otherwise, does not necessarily constitute or juply its endorsement, recommendation, or favoring by the United States Govermment or any agency thereof, or The Regents of the University of California. The views and opinions of authors expressed herein do not necessarily state or reflect those of the United States Government or any agency thereof or The Regents of the University of California. 